\title{
REMOTE SENSING AND ITS APPLICATION IN AGRICULTURAL PEST MANAGEMENT
}

M.C. Acharya ${ }^{1}$ and R. B. Thapa ${ }^{2}$

\section{ABSTRACT}

Agricultural production is significantly affected by biotic- living organisms, such as predator, parasites, pathogens and abiotic factors, like temperature, humidity, rainfall etc. To manage the pests, monitoring and forecasting has been an integrated part of the crop production system in developed countries. In recent years, remote sensing has become popular in pest monitoring, yield forecasting, and early warning to crop growers for timely management of potential pests in agriculture. This paper highlights basic functioning of remote sensing and its application in agriculture with main emphasis on pest management.

Key words: Remote sensing, precision agriculture, pest management, yield prediction, early warning

\section{INTRODUCTION}

Remote sensing refers to noncontact measurements of radiation reflected or emitted from agricultural fields, which are based on the interaction of electromagnetic radiation with soil or plant material. It is an outgrowth of aerial photography (Andreo, 2013). Remote sensing, today, incorporates new technologies that provide increasingly efficient, complete, accurate, and timely information. These new technologies, together with historical photographs, provide the information as a practical management tool for sitespecific management of crops (Cassady et al., 2002). The supply of remotely sensed data greatly increased with the launch of the Earth Resources Technology Satellite (ETRS)-I in 1972 (Aggarwal, 2004). From an orbit of 570 miles above the earth, the satellite can complete a full observation of earth every 18 days. Its multispectral imagery is collected in four visible and infrared wavelength bands of 100 mile wide passes over the earth. This source of data has opened a new dimension to the capability to obtain information about earth resources, particularly crops. The corn blight watch experiment (NASA, 1974) conducted by several agencies of NASA and USDA and others provided a prototype remote sensing system, integrating technique of sampling, data acquisition, storage, retrieval, processing, analysis and information dissemination in a quasi operational system environment (MacDonald et al., 1972). Remote sensing along with Global Positioning Systems (GPS), Geographic Information Systems (GIS) and Variable Rate Technology (VRT) are additional technologies that scientists can implement to help farmers maximize the economic and environmental benefits of area-wide pest management through precision agriculture (Huang et al., 2008).

\footnotetext{
${ }^{1}$ Senior Plant Quarantine officer, Department of Agriculture.

${ }^{2}$ Professor (Entomology), Institute of Agriculture and Animal Science, Rampur, Chitwan, Nepal.
} 
Early warnings and forecasting based on biophysical methods provide appropriate time for managing pest damage and can thus minimize crop loss, optimize pest control and reduce the cost of cultivation (Prasad and Prabhakar, 2012). The results showed that remote sensing procedures could quantitatively recognize corn leaf blight over broad areas. Hence, the most promising application of remote sensing technology is its ability to obtain information about agricultural crop production system. With a minimum amount of ground sampling, remote sensing data permit identification and area measurements of crops, assessment of crop stress, pest damage, yield forecasts, range surveys and mapping of major soil boundaries including many non- agricultural applications. According to Fitzgerald (2000), multi spectral remote sensing (MRS) allowed farmers to detect early infestation of mites in large scale cotton fields due to color shifts and changes in canopy appearance over time. Now-a-days, computer-based systems have increased the speed and accuracy of forecasting, and minimizing its costs.

\section{METHODOLOGY}

Available and relevant literature were gleaned through Google search and other various sources, i.e. various journals, websites, published reports and theses including institutions working in the field of climate, GIS, and remote sensing for gathering necessary information especially in line to basic principles of remote sensing and its potential use in agriculture and crop pest management aspects. Valuable information have been extracted and presented in this article.

\section{BASIC PRINCIPLE OF REMOTE SENSING}

\section{FUNCTIONING OF REMOTE SENSING}

Electromagnetic energy refers to all energy that moves with the velocity of light in a harmonic wave pattern. The wave concept explains the propagation of Electromagnetic energy, but this energy is detectable only in terms of its interaction with matter. In this interaction, Electromagnetic energy behaves as though it consists of many individual bodies called photons that have such particle-like properties as energy and momentum (Sabins, 1976). Using different kinds of sensors of electromagnetic radiation (EMR), from aerial photographs and satellites, one can remotely collect data and analyze them to obtain information about the object or phenomenon sensed. The functioning of the remote sensing is shown in Figure 1. This includes data acquisition and analysis. Satellite maintains its energy through self emission or from huge energy source sun with propagation of energy through atmosphere and losses due to absorption, scattering etc. (Tempfli et al., 2009). 


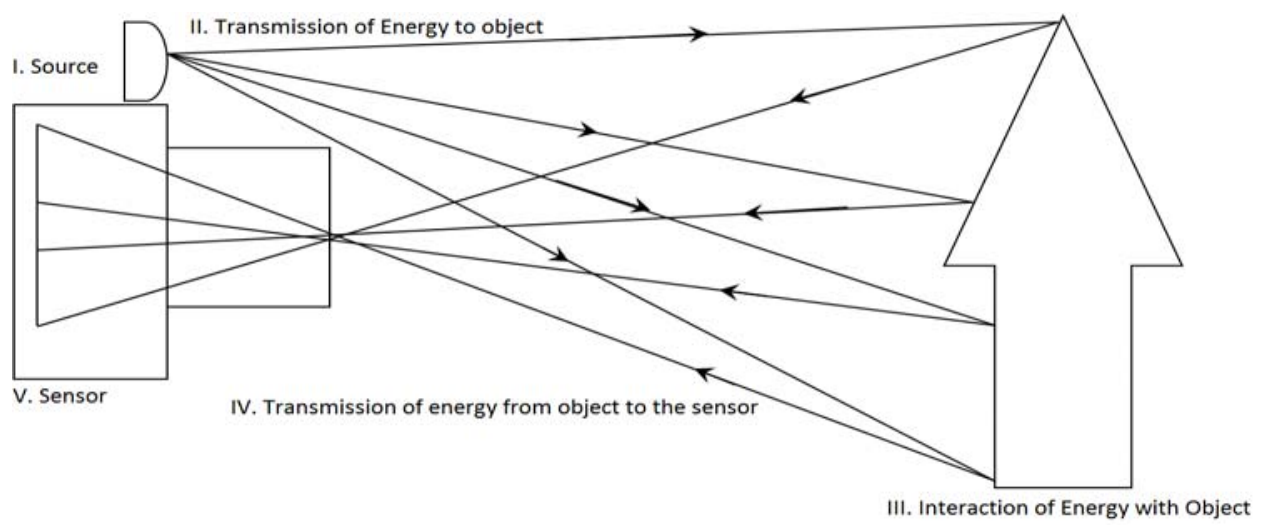

Figure 1. Working of a camera with flash gun (Process of data acquisition)

\section{PHYSICAL BASIS FOR REMOTE SENSING}

The physical basis for remote sensing is the distinctive character of electromagnetic radiance from natural and manmade scenes (Holmes and MacDonald, 1969). Remote sensing in this sense is defined as the acquisition of information about the earth's surface from measurements of radiated energy made by aircraft-or spacecraft-borne sensors. The major objective of remote sensing is to detect, measure, record and analyze energy in selected portions of the electromagnetic spectrum (Figure 2). The variations in electromagnetic fields that can be measured and used to discriminate among objects are spectral, spatial and temporal (Landgrebe, 1973). Electromagnetic radiation is energy propagated through space between electric and magnetic fields. The electromagnetic spectrum is the extent of that energy ranging from cosmic rays, gamma rays, X-rays to ultraviolet, visible, and infrared radiation including microwave energy (Shannon, 2000). Out of the electromagnetic spectrum, the region from $0.3 \mu \mathrm{m}$ to $100 \mu \mathrm{m}$ is used for remote sensing. The electromagnetic spectrum of greatest interest to use in remote sensing is the optical wavelengths, which extend from 0.3-15 $\mu \mathrm{m}$. This is divided into different reflective

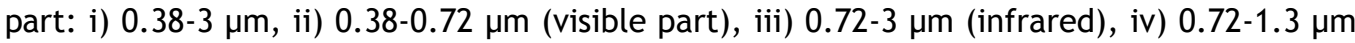
(near infrared), v) 1.3-3.0 $\mu \mathrm{m}$ (middle infrared) and emissive part: 7-15 $\mu \mathrm{m}$ far infrared (emissive/ thermal infrared). The visible portion extending from 0.4-0.7 $\mu \mathrm{m}$ is the most familiar because our eyes are sensitive to radiation at those wavelengths. However, other portions of the spectrum are equally important for remote sensing because of the level of energy reflected or emitted from materials normally varies with the wavelength throughout the spectrum (Tempfli et al., 2009). 


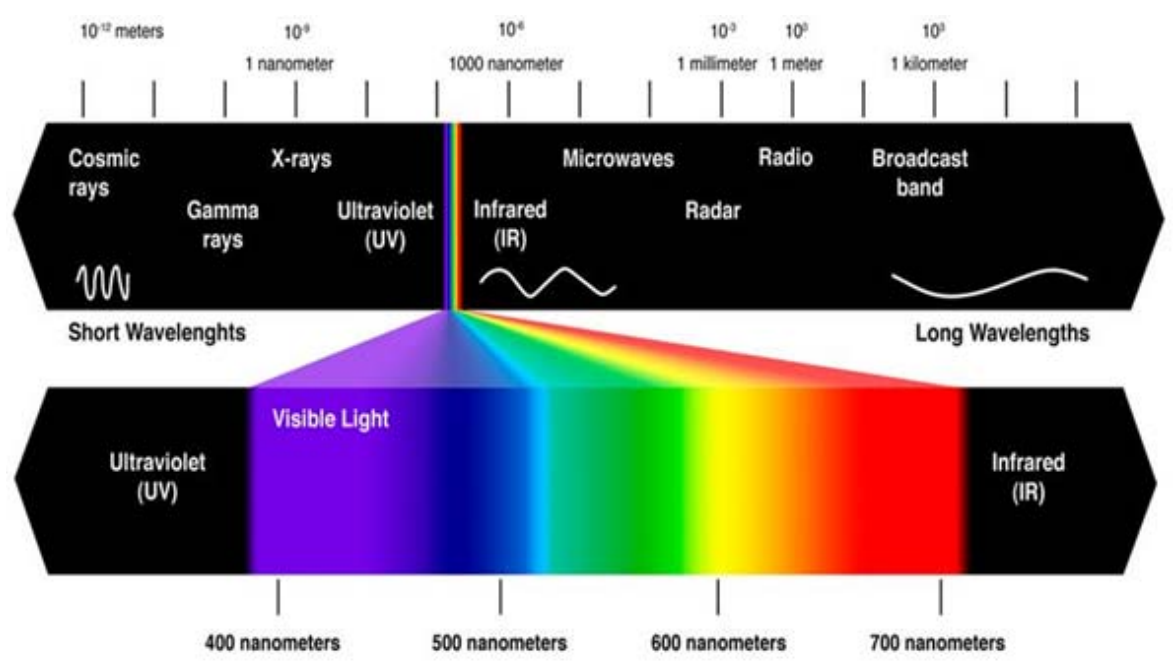

Figure 2. Electromagnectic Spectrum (Source: Zamy Zuly, 2013 "The Electromagnetic Spectrum". Retrieved December 3, 2013, from www.zulyzami.com/The+ Electromagnetic + Spectrum)

The sun is the most important source of EMR for remote sensing and emits radiation as a lack body at about 6000k. In the case of earth, the surface material (soil, water and vegetation) radiate about $300 \mathrm{k}$. This is thermal IR having its peak at about $9.7 \mu \mathrm{m}$ and can be sensed by radiometers and scanners. Solar radiation, on the other hand, has its peak at about $0.5 \mu \mathrm{m}$. When the sun is present we observe terrestrial features by virtue of reflected solar energy. Certain sensors (i.e. Radars) supply their energy to illuminate features under observation such systems are called active systems as distinct from passive systems which observe features in natural light.

When radiation falls on the earth's surface three major types of interactions occur: i) a part is reflected, ii) another part is absorbed, and iii) remaining part is transmitted. The energy balance is expressed as: $\mathrm{El}(\lambda)=\mathrm{ER}(\lambda)+\operatorname{EA}(\lambda)+\mathrm{ET}(\lambda)$, Where, $\mathrm{El}=$ Incident energy (near a given $\lambda), E R=$ Reflected energy, $E A=$ Absorbed energy, and, $E T=$ Transmitted energy. In remote sensing, we are largely concerned with reflected radiation which is the radiation that causes our eyes to see colors, causes infrared film to record vegetation, and allows radar images of the earth to be created (Shannon, 2000). It is primarily concerned with diffuse reflection because it contains spectral information dependent on the color of the reflecting surface. The reflectance characteristics of earth surface features are often expressed quantitatively in terms of $R_{\lambda}$ called spectral reflectance defined as the ratio of the energy reflected from an object to the energy incident upon the object, i.e. $R_{\lambda}=(E R$ $(\lambda) /\left(E I(\lambda)\right.$. A plot of $R_{\lambda}$ of a surface as a function of $\lambda$ is called a spectral reflectance curve which is of great importance (Tempfli et al., 2009). 


\section{PHYSIOLOGICAL BASIS OF REMOTE SENSING}

This includes leaf reflectance, canopy reflectance, crop canopy temperature and vegetation indices, which are outlines as follows:

Leaf reflectance: An understanding of physiological properties of plants and their interaction with incident radiation is important in crop condition assessment through remote sensing. The striking features of leaf reflectance are high absorbance in the blue $(0.45 \mu \mathrm{m})$, red $(0.65 \mu \mathrm{m})$ and reduced absorbance in the green $(0.55 \mu \mathrm{m})$, high reflectance in the NIR $(0.75-1.2 \mu \mathrm{m})$ and again very high absorbance in the FIR regions of the spectrum (Figure 3). The absorbance in the visible region of EMR spectrum is due to plant pigments (carotenoids, chlorophyll $\mathrm{a}$ and chlorophyll $\mathrm{b}$, which is called photo synthetically active radiation (PAR). The abrupt increase in reflectance near $0.75 \mu \mathrm{m}$ is due to internal structure of the leaf and the canopy geometry. Any physiological disturbance in leaf leads to an increase in leaf reflectance in the visible region. The leaf moisture is largely the cause of very strong absorption throughout the FIR region (1.3-2.5 $\mu \mathrm{m})$ (Liew, 1997).

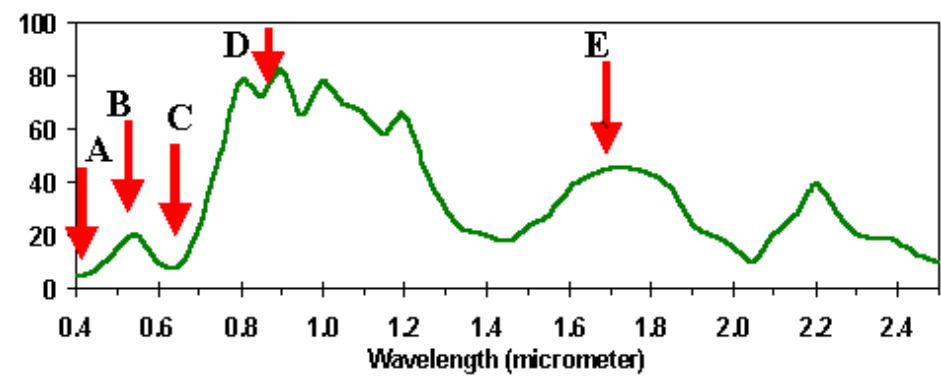

Figure 3. Typical reflectance spectrum of vegetation (The labelled arrows indicate the common wavelength bands used in optical remote sensing of vegetation: A: blue band, B: green band; C: red band; D: near IR band; E: short-wave IR band (Source: Liew, 1997)

Canopy reflectance: Robust empirical relationships between remotely sensed canopy reflectance and ground-measured biophysical and biochemical parameters of vegetation have been established via different models. Mathematical functions of two or more spectral bands are used rather than direct reflectance data to minimize the negative impact of interfering factors, such as the surrounding land cover, bare soil, or climatic/atmospheric conditions. These functions are called vegetation indices (Vls), each designed for optimal correlation with a particular vegetation feature (Malenovsky et al., 2009).

Crop canopy temperature: Colaizzi et al. (2010) demonstrated radiometer footprint model to estimate sunlit and shaded components for row crops. Crop evapo-transpiration is the basic physiological process that determines the canopy temperature when an 
aerodynamically rough canopy has sufficient supply of water; leaves are generally cooler than the ambient air because of the heat lost through transpiration. However, when the moisture in the root zone becomes limiting under soil moisture stress, evapo-transpiration decreases due to partial closure of stomata and thus the canopy's temperature rises relative to that of non stressed crop. The difference between canopy and air temperature (Tc-Ta) measured at the time of maximum surface temperature could be used as an indicator of crop water status and crop yield. The most useful wavelength region for canopy temperature measurement and quantification is the thermal infrared band (8-14 $\mu \mathrm{m})$. Currently thematic mapper (TM) of LANDSAT, Advanced Very High Resolution Radiometer (AVHRR), On Board US National Oceanic and Atmospheric and Administration (NOAA) satellites and the Indian National Satellite (INSAT) provide data in thermal infrared channels.

Vegetation indices: A vegetation index is an indicator that describes the greenness- the relative density and health of vegetation - for each picture element, or pixel, in a satellite image. Rouse (1973) developed a transformation of radiance values of near infrared (NIR) and red $(\mathrm{R})$, the two contrasting spectral bands and called it vegetative index ( $\mathrm{VI})$. The ability of an optical sensor to resolve features within specific wavelengths of the optical spectrum and slice wavelengths into smaller increments is referred to as a sensor's spectral resolution. The main purpose of spectral vegetation indices is to enhance the information contained in spectral reflectance data, by extracting the variability due to vegetation characteristics (i.e. LAl, vegetation cover) and to minimize soil, atmospheric, and sun-target-sensor geometry effects (Moulin and Guerif, 1999). The greenness vegetation index (GVI) and perpendicular vegetation index (PVI) developed subsequently can be employed to monitor the photo synthetically active biomass as well as the vigor and the condition of plant canopy. The $\mathrm{VI}$ is generated from the data obtained by satellites, like LANDSAT, SPOT, IRS-IA, NOAA and AVHRR. The normalized difference vegetation index (NDVI) of AVHRR sensor is the most often used for monitoring the vegetation status on a global scale. NDVI is the difference in the radiance values of NIR and visible spectrum divided by their sum.

\section{TYPES OF REMOTE SENSING}

Beginning with the early use of aerial photography, remote sensing has been recognized as a valuable tool for viewing, analyzing, characterizing, and making decisions about our environment. In the past few decades, remote sensing technology has advanced on three fronts: 1) from predominantly military uses to a variety of environmental analysis applications that relate to land, ocean, and atmosphere issues; 2) from (analog) photographic systems to sensors that convert energy from many parts of the electromagnetic spectrum to electronic signals; and 3) from aircraft to satellite platforms (Levin, 1999). Conventional remote sensing is of two types: i) Aerial photography, and ii) Satellite imagery. 
Aerial photography: The term, "remote sensing," was first introduced in 1960 by Evelyn L. Pruitt of the U.S. Office of Naval Research (Baumann, 2014). However, the first aerial photograph was taken in 1858, 102 years before the term "remote sensing" came into existence. USDA has been using it operationally since the 1930's to record land use and in soil mapping. The photographs are taken from an aircraft, with the axis of the aerial camera kept vertical, horizontal or oblique. However, for environmental survey purpose vertical photographs are suitable for obtaining uniform coverage. The photographs are taken from an aircraft flying at a particular height (Baumann, 2014).

Even today with products from the space systems competitively priced, aerial photography remains a powerful and sometimes optimum tool to use for both routine and specialized applications. Two variants of aerial photos, each obtainable in black and white or color, are the vertical (sees Earth straight downward) and the oblique (sees at various angles, usually less than $45^{\circ}$ ). Photography commonly takes place in the visible but film sensitive to the very near infrared or ultraviolet allows image-taking in those spectral regions. The uses of aerial photography in the management of biosphere reserve make this type of remote sensing very important. Its advantages are superior spatial resolution, relative simplicity of photography and film processing, relatively low cost equipment, and providing considerable amount of information. But its disadvantage is the range of sensitivity is confined by film emulsion technology to the visible and near infrared regions ( 0.4 to $1 \mu \mathrm{m}$ ) (Short, 2005).

Satellite Imagery: Today, many satellites, with various remote sensing instruments, monitor the Earth's surface. These satellites and their respective remote sensing programs can trace their origins back to the CORONA and Land sat programs. CORONA was a secretive military reconnaissance program that continues to the present time through the advanced Keyhole satellites and Landsat was an open Earth resources program that also continues through more advanced Landsats and other satellite resource monitoring programs. The period from 1960 to 2010 has experienced some major changes in the field of remote sensing. As satellites can cover much more land space than planes and can monitor areas on a regular basis. With advancement in technology, imagery became digital in format rather than analog. The digital format made it possible to display and analyze imagery using computers; sensors were becoming available that recorded the Earth's surface simultaneously in several different portions of the electro-magnetic spectrum. One could now view an area by looking at several different images, some in portions of the spectrum beyond what the human eye could view. This technology made it possible to see things occurring on the Earth's surface that looking at a normal aerial photograph one could not detect. The turbulent social movements of the 1960s and 1970s awakened a new and continuing concern about the changes in the Earth's physical environment. Remotely 
sensed imagery from satellites - analyzed and enhanced with computers - made it possible to detect and monitor these changes (Baumann, 2009).

The multispectral scanners in the satellites scan the earth line by line in many discrete light quality ranges (bands of spectrum) in the visible and thermal portions of the spectrum $(0.3$ to $14.0 \mu \mathrm{m})$. A scan line consists of several measurement values representing the energy reflected or emitted from the discrete blocks of surface area. The values are recorded on magnetic tapes which can be directly used in a computer for analysis. A computer can handle multispectral data simultaneously and make decisions about identification of surface features using statistical approaches.

\section{APPLICATION OF REMOTE SENSING IN PEST MANAGEMENT}

The factors which favor the development of pests and their effect on plant parameters that are detectable by remote sensors are shown in Figure 4.

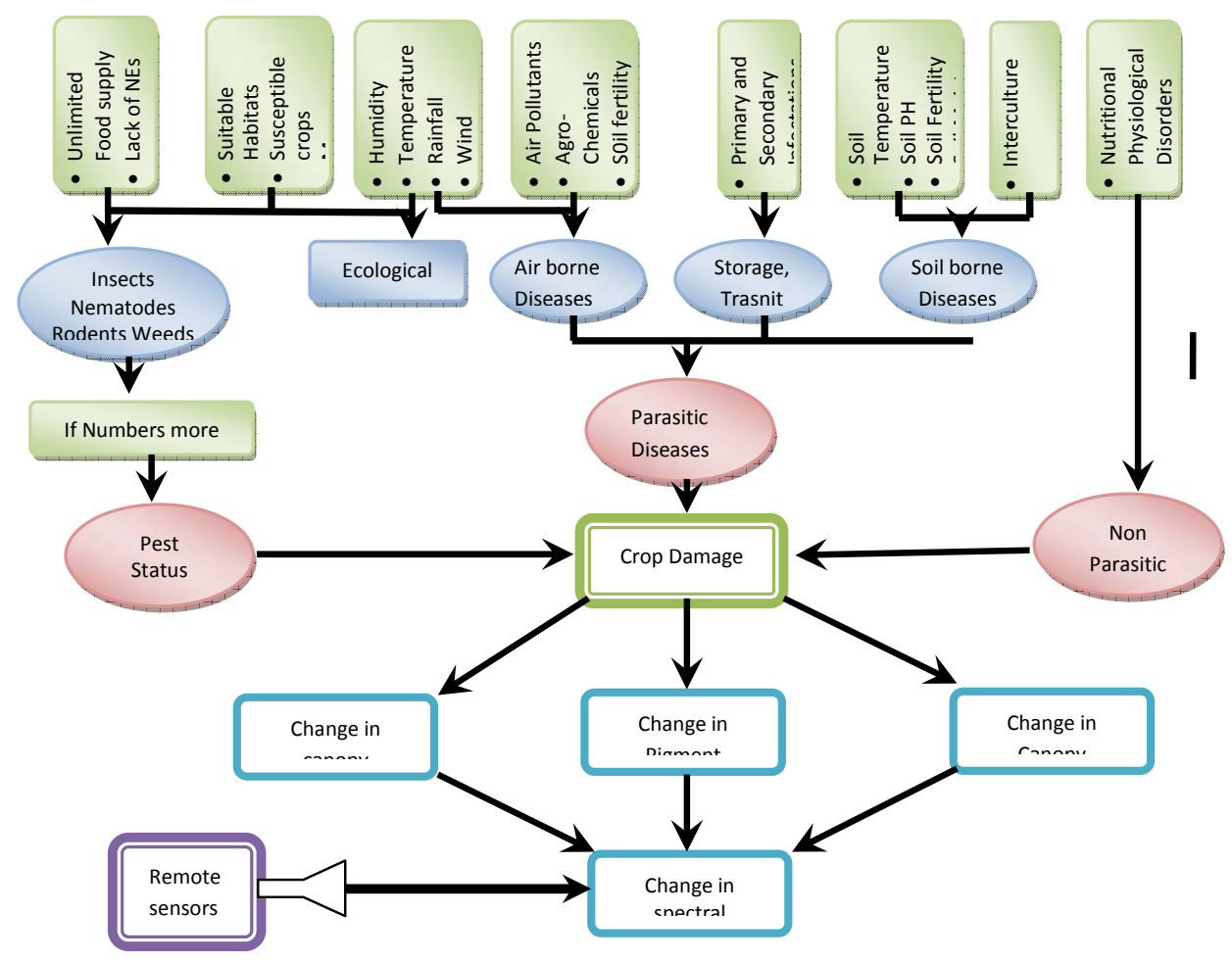

Figure 4. Development of crop pests and diseases leading to crop damage and its detection through remote sensing (Source: Nageswara Rao, 1988) 
Remote sensing can be considered as a fast, non-destructive and relatively cost-effective method to study biophysical and biochemical parameters of vegetation across vast spatial areas (Ngie et al., 2014). Remote sensing (including aerial photography) can supply baseline information for land-use and other forms of spatial planning in areas where maps are not available and it is used as an input for the modeling of alternative land use options (i.e. agriculture or biological conservation) (Leeuw et al. 2010). Many of the potential research and management applications of remote sensing are tactical, i.e. they involve responses to particular conditions or situations that arise during the course of the season, such as insect pest management. The tactical questions often involve determining how field is changing, i.e. detecting an emerging pest population. Detecting change with remote sensing involves collecting images frequently and comparing them with previous images. Thus, the values from a location in one image may be compared with values from the same location in other images. Calibration of remotely sensed images is generally accomplished by laying out large panels of known properties that then appear in the image. The normalized difference vegetation index (NDVI) is used for the purpose as a most common index for multispectral data.

\section{PRECISION SURVEY IN AGRICULTURE}

Twenty five years of remote sensing in precision agriculture has been reported by Mulla (2013). Various types of precision systems have been applied in agriculture as shown in Figure 5. Based on the studies of over decades in USA, remote sensing has been used for various purposes of precision surveys (Eriction, 2014). Several studies have shown that the NDVI calculated from NOAA-AVHRR data has very strong correlation to the primary productivity of the cereal crop yields.

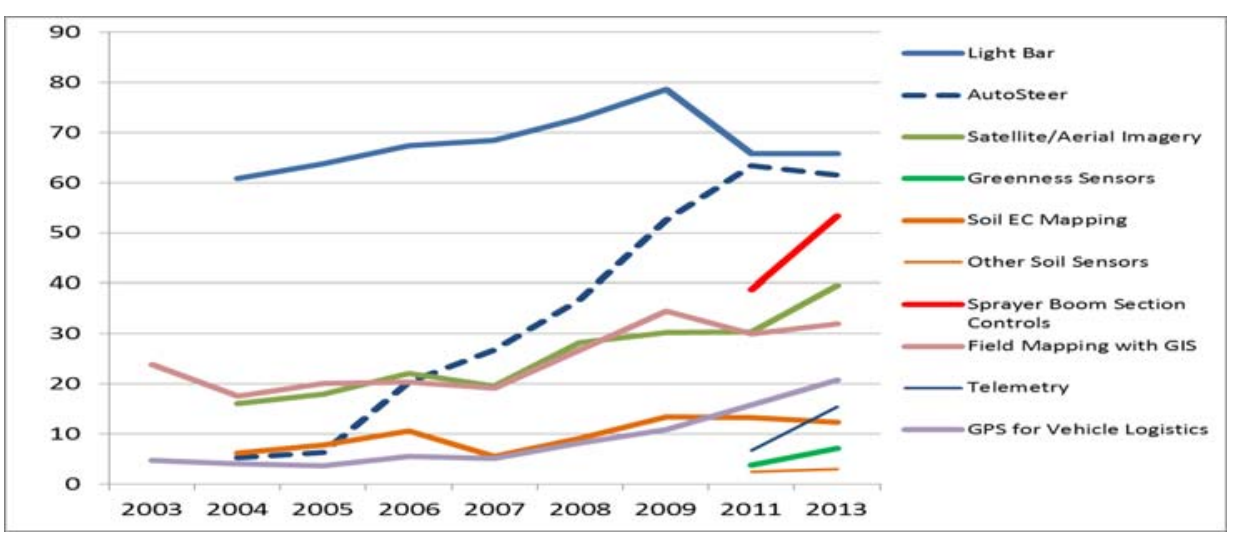

Figure 5. Decades of precision survey in agriculture (Source: Eriction, 2014) 
Remote sensing of insect pests of fruit trees was pioneered in 1968, especially in citrus, detecting the insect infestation using presence of sooty mould. The use of remote sensing in agriculture in India started with the detection of wilt disease in coconut at Kerala Coast (Dakshinamurty et al., 1971). But later main emphasis was shifted to crop acreage estimation, crop condition assessment and yield forecasting using different crop simulation models (Shin et al., 2009; Basso et al., 2010; 2012). Some work has been done on forecasting of desert locust. Riley (1989) provided an exhaustive review on the use of remote sensing in the field of entomology. Optical and video imaging in near-infrared and microwave regions were used to quantify even the nocturnal flight behavior of $\mathrm{H}$. armigera (Riley et al., 1992). Recently, forecasting methods of potato late blight, apple scab, mango powdery mildew and rice blast are available (Sinha and Banik, 2009). The application of remote sensing in pest monitoring, detection, early warning and management aspects in the field of agriculture are summarized as follows:

\section{Survey of ecological conditions and forecasting locusts}

Over the years, strategies of Desert Locust control have evolved from curative efforts to an emphasis on prevention, i.e. finding and treating infestations before they form large hopper bands and swarms. This requires regular monitoring of locust breeding areas and the ability to quickly mount small scale control operations in many of the 60 countries affected by the Desert Locust. It has only been during this century that our understanding of the Desert Locust and its relationship with the environment has increased to a point that allows for better management of this pest through improved strategies of monitoring and control. Tucker et al. (1985) demonstrated potential of satellite remote sensing of ecological conditions of survey and forecasting the desert locust activity. Remote sensing imagery can assist in the detection of green vegetation and thereby help to guide ground survey teams. Since the late 1980s, imagery has been used in parts of West Africa and in the Red Sea area (Cressman, 1998). The use of satellite remote sensing technology has raised many hopes for forty years to support locust monitoring. The joint use of remote sensing data and of locust data issued from RAMSES for a period of 43 years (1965-2008) proved to be crucial. These locust data helped to prioritize the different areas according to their interest for the locust ecology. They allowed researchers to focus only on areas of major interest for the preventive control of this species (Lazar et al., 2015).

\section{Assessment of crop infested with insect pests}

In order to use visible and infrared images to detect stress in rice production caused by BPH infestation, several remote sensing techniques have been developed. Initial recognition of pest infestation by means of remote sensing will spreads, for precision farming practice. Normalized Difference Vegetation Index (NDVI), Standard difference indices (SDI) and Ratio Vegetation Index (RVI) are used for analyses using ENVI 4.8 and SPSS software. Using these 
indices as indicator can clarify the threshold for zoning the outbreaks (Ghobadifar et al., 2014).

The normalized difference vegetation index (NDVI) has been a popular index with some limitations to estimate LAl across diverse ecosystems. Cotton grown as a mono-crop in Guntur and Prakasham districts in Andhra Pradesh was severely infested by white fly, Bemisia tabaci during kharif 1985. Landsat-5 (MSS \& TM) false color composites were used for the assessment of the condition of the cotton crop. The technique involved visual detection of changes in the red color on Landsat FCC of 28/11/1985 in comparison to that on Landsat FCC of 11/12/1984, a normal year. The temporal chromatic profile techniques supported by ground truth data collected on 9/12/1985 were used in delineating the affected areas. Regions showing $50-80 \%$ damage by the pest could be easily identified. Huwang et al. (2008) suggested that land surface temperature (LST) and modified normalized difference water index (MNDWI) were of great potential in discriminating and monitoring the aphid damage degree over a large area, only using thermal infrared band and multi-spectral satellite images.

\section{Early detection of wild hosts and reducing the population build up}

Wild radish, winter peas, wild mustard, vetch and curly duck harbor insects that later attack cotton and soybean in Mississippi State, USA. Remote sensing has been used to detect the wild host plant areas early in season and also to detect pest infestations within cotton fields and crop maturity levels related to these pest infestations during the cropping season. Cotton generated more than $\$ 483$ million and soybean $\$ 174$ million to the state economy (Ray, 2001).

\section{Early detection of insect pests}

Early detection of the pest infestation could reduce overall applications of pesticides using variable rate application technology, thus saving the producer's money. During noncropping periods, tarnish plant bugs feed and reproduce on broad leaf wild host plants. Remote sensing and spectro-radiometry showed distinct differences between broad leaf hosts and non-host grasses. High spectral resolution remote sensing imagery with more bands and narrower bandwidth is required for remote sensing diagnosis of crop disease stress (Qin et al., 2003).

\section{Locating hot spots of pest infestation in crops}

Preliminary remote sensing revealed spider mite infestations reddish hot spot patterns in cotton fields and discerned them from healthy and drought stressed cotton in 1999. This information may be useful in the targeting of precision pesticide applications. Because spider mites and aphids occur in heterogeneous areas of the fields, it is possible that these 
"hot spots" can be differentiated from other sources of variation, using the wavelengths in the NIR (Reisig and Godfray, 2006)

\section{Monitoring conditions favourable for pest outbreak}

Various factors such as intensive cultivation, mono-cropping, changing weather conditions and indiscriminate use of pesticides have resulted in frequent outbreaks of crop pests and diseases causing huge crop losses. Minimizing these losses is one way of enhancing grain production and remote sensing tool has been found very useful in monitoring large areas frequently. The Earth observing systems are useful in monitoring weather and ecological conditions favorable for crop pests and diseases. Weather conditions such as temperature, humidity (moisture), sunshine hours (light) and wind play major influence on the densities of pest population and their natural enemies. Among the weather parameters that can be remotely sensed, type of cloud, extent of cloud cover, cold cloud duration (a surrogate for rainfall) are the most easily retrievable. Such information was used by phytopathologists to study rust diseases of wheat crop (Das, 2013).

\section{Remote sensing of individual species of insects}

Locusts: Traditional ground locust surveys are inadequate to address the enormous spatial scale of the locust problem in a limited window of time dictated by the pest's development. Remote sensing (satellite information) appears a promising tool in locust monitoring. Satellite data are increasingly used for monitoring and forecasting two locust species, the desert and the Australian plague locust. (Latchininsky, 2013).

Moth flight: It is extremely difficult to observe and quantify high altitude insect movements using traditional entomological techniques. Thus, the deployment of specialpurpose entomological radars in the late 1960s (Schaefer, 1976) has greatly added to our knowledge of insect flight behaviour at high altitudes. Entomological radar observation programs have, up until now, been strongly focused on large insects (moths, migratory grasshoppers) flying under stable boundary layer conditions at night (Wood et al., 2008). RADAR observation of Spodoptera exempta have shown that this species at least in its gregarious phase is an obligate wind borne migrant and that the aggregation of flying moths, particularly by storm front outflows, is a major factor in the outbreak of caterpillars. By contrast, Heliothes armigera, in India shows little tendency to undertake long range migration above the altitude at which wind speed exceeds flying speed.

Aphids and spider mites: Remote sensing was used for detection of cotton aphid and spider mite infested cotton in the San Joaquin Valley (Reisig and Godfrey. 2006). Wavelengths in the NIR were fair to moderately accurate predictors of aphid- and miteinfested cotton. Concentration of airborne aphids up to $1200 \mathrm{~m}$. above the sea level have been detected by using very powerful $10 \mathrm{~cm}$ RADARS. 
Plant hoppers and leaf hoppers: Millimetric radar studies in Philippines have shown that plant hoppers and leaf hoppers associated with rice engage predominate in short range flights. Prasannakumar et al. (2013) in India used hyperspectral remote sensing to detect the brown planthopper (BPH), Nilaparvata lugens (Stal.), stress on rice plants under glasshouse as well as field conditions and revealed that variation in plant reflectance due to BPH damage was smaller at shorter wavelengths $(350-730 \mathrm{~nm})$ and larger at longer wavelengths, viz., NIR (740-925 nm) followed by mid infrared (MIR) (926-1800 nm), which indicated the possibility of detection of BPH stress on rice and thereby issuing prompt forewarning to stakeholders.

\section{Survey of insect pests of crops and fruit trees}

Sooty mould has been used to indicate the presence of corn leaf aphid, Rhopalosiphum maydis and sweet potato white fly, Bemicia tabaci Glover. In a study, photographs were taken from 2000 meters and different levels and areas if infestation were successfully measured with the aid of photographic enhancements and computerized area estimation methods. The white fly induced sooty mould could be detected on cotton from 300 meters and photographs from 2000 meters yielded good resolution of mould growth patterns. A number of insect pests like soft scale, Coccus hesperidium, infesting citrus groves; citrus mealy bugs, Phenococcus citri, citrus black fly, Aleurocanthes woglumi produce honey dew that serves as host medium for sooty mould fungus. This mould blackens foliage and thus provides a clue for quick detection of insects by aerial photography. Wavelengths in the NIR were fair to moderately accurate predictors of aphid and mite infested cotton (Reisig and Godfrey. 2006).

\section{Mapping of geographical distribution of pests along with GIS}

GIS is another tool, which can be used effectively for mapping geographical distribution of pests, delineating the hotspot zones. GIS methods can be divided into two sub groupsRemote Sensing and Digital Cartography. Fundamentally, GIS techniques create data abstractions to describe the real world life systematically classifying features into a series of thematic layers. Each layer can be evaluated independently or features between two or more layers can be analyzed together. Remote sensing has also been used in conjunction with GIS for monitoring changes in crop conditions. Mino et al. (1998) used multi-temporal satellite data to distinguish grasslands of different ages, monitor changes in management and evaluate grassland quality. District wise geographical maps of rice and cotton pests have been prepared at NCIPM (Kanojia et al., 2000).

\section{As an aid in precision farming}

Precision Farming (PF), also called Precision Agriculture (PA) or site specific crop management (SSCM) is an integrated information- and production-based farming system that is designed to increase long term, site specific and whole farm production efficiency, 
productivity and profitability while minimizing unintended impacts on wildlife and the environment" (Earl et al., 1996). The basic principle of PF is to maximize the efficiency of inputs as measured by outputs, which is to optimize inputs according to field variability in order to maximize yields diminishing production costs and environmental impacts of agricultural practices, by giving the right amount of input at the right place and the right time. Rapid advances in remote sensing for precision agriculture have occurred over the last twenty five years. Satellite imagery has improved in spatial resolution, return visit frequency and spectral resolution. Aerial hyperspectral imagery has revolutionized the ability to distinguish multiple crop characteristics, including nutrients, water, pests, diseases, weeds, biomass and canopy structure (Andreo, 2013). There is a significant potential in precision agriculture for combining archived remote sensing data with realtime data for improved agricultural management (Thenkabail, 2003).

\section{Rainfall and outbreak of pests}

Flying moths of the east - African armyworm, Spodoptera exempta, are concentrated by convergent winds associated with rain storms and the subsequent mass laying of the aggregated moths leads to massive outbreaks of destructive caterpillars. Remote sensing of rain storms in the appropriate areas thus presents the prospect of rapidly locating potential outbreaks (Holt et al., 2000).

\section{Survey of habitats of insect vectors of animal diseases}

Remote sensing imagery (from high-resolution aerial photography to coarse-resolution satellite imagery) when combined with GIS spatial analyses techniques can play an important role in existing vector surveillance and control programs at local and regional scales (Washino and Wood, 1993). By applying the remote sensing and GIS techniques for mapping vector habitats, vectors' presence, abundance and density, assessing the risk of vector-borne diseases, disease transmission, spatial diffusion, we can find the root cause of the disease infection, and source of infection. (Palaniyandi, 2012). With the availability of multispectral, multi-temporal and real time satellite data products, GPS assisted georeferenced epidemiological data are being integrated under the umbrella of the GIS software for mapping distribution of vector borne diseases (including malaria, Japanese encephalitis, filariasis, schistosomiasis, Ross river virus disease etc.

\section{CONCLUSIONS}

Remote sensing has been used to provide useful information on crop condition, detection of development of pest population in remote and inaccessible areas. Its aims is to bridge gaps in the existing systems securing a regular information flow about the areas affected by insect pests and diseases and other yield reducing factors on a nationwide basis. Based on research findings on some crop pests and diseases, it can be used in agriculture insect pest 
management decisions, timely planning and getting different information in many specific areas such as i) survey of ecological conditions and forecasting insect pest outbreaks, ii) assessment of crop condition, iii) early detection of wild hosts and reducing the population build up, i.e. radish, winter peas, wild mustard etc. harbouring bugs attacking cotton and soybean, iv) early detection of insect pests, i.e. tarnish bugs in cotton fields, v) locating hot spots of pest infestation, i.e. spider mite infestation in cotton, vi) monitoring conditions favourable for pest outbreak and take management decisions in advance, vii) remote sensing of individual species of insects, i.e. locusts, moths and aphids etc., viii) survey of insect pests of crops and fruit trees, i.e. aphids in corn, scales and mealy bugs in citrus fields, ix) mapping geographical distribution of pests, along with GIS, $x$ ) as an aid in precision farming, $\mathrm{xi}$ ) rainfall and outbreak of pests, and xii) survey of habitats of vectors of vertebrate pests.

Forecasting system for insect pests in Agro-ecosystem provides opportunity to inform farmers about possible out breaks for preparedness and taking of timely action to apply biocontrol agents, mechanical means and pesticides, which ultimately cuts down the cost of production and serves as a tool in precision farming. Hence, recent advancements in the field of remote sensing provide ample scope to use this technology in agriculture for pest monitoring, detection and timely management with high precision.

\section{REFERENCES}

Aggarwal, S., 2004. Earth Resource Satellites. In: M.V.K. Sivakumar, P.S. Roy, K. Harmsen and S.K. Saha (eds.) Satellite Remote Sensing and GIS Applications in Agricultural Meteorology. Proceedings of the Training Workshop 7-11 July, 2003, Dehra Dun, India. World Meteorological Organization, Geneva Switzerland. pp. 39-67.

Andreo, V., 2013. Remote sensing and geographic information systems in precision farming. Available: http:// aulavirtual.ig.conae.gov.ar/ moodle/ pluginfile. php /513/ mod_page/ content /71/seminario_andreo_2013.pdf (Retrieved 16 April 2015).

Basso, B., Fiorentino C., Cammarano D., Cafiero G. and Dardanelli J., 2012. Analysis of rainfall distribution on spatial and temporal patterns of wheat yield in Mediterranean environment. European Journal of Agronomy 41: 52- 65.

Basso, B., Cammarano D., Troccoli A., Chen D. and Ritchie J.T., 2010. Long-term wheat response to nitrogen in a rainfed Mediterranean environment: Field data and simulation analysis. European Journal of Agronomy 33: 132-138.

Baumann, P.R., 2014. History of remote sensing, Aerial Photography Part I. Available: http://www.oneonta.edu/faculty/baumanpr/geosat2/ RS\%20History\%20I/ RS- History Part1.html (Retrieved on 15 April 2015).

Baumann P.R., 2009. History of remote sensing, Satellite Imagery Part II. Available: http://www.oneonta.edu/faculty/baumanpr/geosat2/RS\%20History\%20II/ RS- History-Part2.html (Retrieved 15 April 2015). 
Cassady, W.W. and Palm H. L., 2002. Precision agriculture: Remote sensing and ground truthing. Available: http://extension.missouri.edu/p/EQ453 (Retrieved 16 April 2015).

Colaizzi, P. D., O’Shaughnessy S. A., Gowda P. H., Evett S. R., Howell T. A., Kustas W. P. and Anderson M.C., 2010. Radiometer footprint model to estimate sunlit and shaded components for row crops. Agronomy Journal 102: 942-955.

Cressman, K., 1998. Monitoring locusts in the Middle East: An overview. Yale F\&ES Bulletin 103:123140.

Dakshinamurty, C., Krishnamurthy B., Summanwar A.S., Shanta P. and Pisharoty P.R., 1971. Remote sensing for coconut wilt. pp. 25-29. In: Proceedings of 6th International Symposium on Remote Sensing of Environment. Environmental Research Institute at Michigan, Ann Arbor, U.S.A.

Das, H.P., 2013. Sattellite-Based Agro-Advisory Service. In: Satellite Remote Sensing and GIS Applications in Agricultural Meteorology. pp. 347-35. Available: http://www. wamis.org/agm/pubs/ agm8/Paper-17.pdf (Retrieved15 April 2015).

Earl, R., Wheeler P.N., Blackmore B.S. and Godwin R.J., 1996. Precision farming - the management of variability. The Journal of the Institution of Agricultural Engineers 51: 18-23.

Eriction, B., 2014. Looking forward from two decades of precision agriculture: The Crop Life/ Purdue University, Survey. Department of Agronomy, Purdue University, USA.

Fitzgerald, G., 2000. Bug checking for mites - from the sky. Australian Cotton Grower 21:29-31.

Ghobadifar, F., Wayayok A., Shattri M. and Shafri H., 2014. Using SPOT-5 images in rice farming for detecting BPH (Brown Plant Hopper). 7th IGRSM International Remote Sensing \& GIS Conference and Exhibition. IOP Conf. Series: Earth and Environmental Science 20. pp. 10

Holmes, R.A. and McDonald R. A., 1969. The Physical Basis of System Design for Remote Sensing in Agriculture. Proceedings of the IEEE 57(4): 629-639.

Holt, J., Mushobozi W. L., Tucker M. R. and Venn J. F., 2000. Modelling African Armyworm Population Dynamics to Forecast Outbreaks. In: R. A. Cheke, L. J. Rosenberg and M. E. Kieser (eds.) Workshop Proceedings on Research Priorities for Migrant Pests of Agriculture in Southern Africa, Plant Protection Research Institute, Pretoria, South Africa, 24-26 March 1999. Natural Resources Institute, Chatham, UK. pp. 151-163.

Huang, Y., Lan Y. and Hoffmann W. C., 2008. Use of airborne multi-spectral imagery for area-wide pest management. Agricultural Engineering International: The CIGR Ejournal. Manuscript IT 07 010. Vol. X. February 2008. pp. 14.

Kanojia, A.K.P., Orameela Devi and Surender Kumar. 2000. Distribution maps of insect pests and diseases of major crops in India. National Center for Integrated Pest Management. New Delhi, India.

Landgrebe, D. A. 1973. A study of the utilization of ERTS-1 data from the Wabash River Basin. Bimonthly Progress Report. Purdue Univ., Indiana, USA.

Latchininsky, A.V., 2013. Locusts and Remote Sensing: a review, Special Section On Advances In Remote Sensing Applications For Locust Habitat Monitoring And Management. J. Appl. Remote Sens. 7(1), 075099 (28 May 2013). doi: 10.1117/1.JRS.7.075099 
Lazar M., Diongue A., Yang J.T., Bahia D.M. and Michel L., 2015. Location and characterization of breeding sites of solitary desert locust using satellite images Landsat 7 ETM+ and Terra MODIS. Advances in Entomology 3:6-15. Published online: January 2015 in SciRes. http://www.scirp.org/journal/ae http://dx.doi.org/10.4236/ae.2015.31002 (Retrieved 16 April 2015).

Leeuw, Jan de, Georgiadou Y., Kerle N., de Gier A., Inoue Y., Ferwerda J., Smies M. and Narantuya D., 2010. The function of remote sensing in support of environmental policy. Remote Sensing 2010, 2, 1731-1750 doi: 10.3390/rs2071731. ISSN 2072-4292. Available: www.mdpi.com/journal/ remotesensing (Retrieved 15 April 2015).

Levin, N., 1999. Fundamentals of remote sensing. $1^{\text {st }}$ Hydrographic data management course, IMO International Maritime Academy, Trieste, Italy Remote Sensing Laboratory, Geography Department, Tel Aviv University, Israel GIS unit, the Society for the Protection of Nature in Israel.

Liew, S. C. 1997. Principles of remote sensing. Centre for Remote Imaging, Sensing and Processing National University of Singapore Blk S17/SOC1 Level 2, Lower Kent Ridge Road Singapore 119260. Available: http://www.crisp.nus.edu.sg/ research/tutorial/ rsmain. htm (Retrieve 15 April 2015).

MacDonald, R.B. Bauer M.E., Allen R.D., Clifton J.W., Landgrebe D.A. and Erikson J.D., 1972. 8th Proc. Symposium on Remote Sensing Environ. pp. 157-190.

Malenovsky, Z, Mishra K. B., Zemek F., Rascher U. and Nedbal L., 2009. Scientific and technical challenges in remote sensing of plantcanopy reflectance and fluorescence. Review Paper. Journal of Experimental Botany 60 (11): 2987-3004. Available: doi:10.1093/jxb/erp156 Advance Access publication (Retrieved 15 April 2015).

Mino, N., Saito G. and Ogawa S., 1998. Satellite monitoring of changes in improved grassland management. Int. J. Remote Sens. 19:439-452

Moulin, S. and Guerif M., 1999. Impacts of model parameter uncertainties on crop re-flectance estimates: A regional case study on wheat. International Journal of Remote Sensing 20: 213218.

Mulla, D.J., 2013. Twenty five years of remote sensing in precision agriculture: Key advances and remaining knowledge gaps- Reviews. Biosystems Engineering 114: 358 -371.

NASA. 1974. Corn blight watch experiment. Summary report. NASA, USDA, Washington DC, USA.

Ngie, A., Ahmad F. and Abutaleb K., 2014. Remote sensing potential for investigation of maize production: Review of literature. South African Journal of Geomatics Vol. 3, No. 2, Aug. 2014. pp. 163-184. Available: http://www.ajol.info/index. php/sajg/issue/view/11348 (Retrieved 15 April 2015).

Palaniyandi, M., 2012. The role of remote sensing and GIS for spatial prediction of vector-borne diseases transmission: A systematic review. Journal of Vector Borne Disease 49:197-204. Available: http://www.mrcindia.org/journal/issues/ 494197.pdf (Retrieved 16 April 2015).

Prasad, Y.G. and Prabhakar M., 2012. Pest monitoring and forecasting. In: D.B. Abrol and U. Shankar (eds.) Integrated Pest Management. CAB International, UK. pp. 41-57. 
Prasannakumar, N.R., Chandar S., Sahoo R.N. and Gupta V. K., 2013. Assessment of Brown Plant Hopper (Nilaparvata lugens) [Stal], damage in Rice using hyperspectral remote sensing. International Journal of Pest Management, 2013, 59 (3):180-188. http:// dx.doi.org/10.1080/09670874.2013..808780. http://www.tandfonline.com/doi/ abs/10. 1080/09670874.2013.808780?journalCode=ttpm20\#preview (Retrieved15 April 2015).

Qin, Z., Zhang M., Christensen T., Li W. and Tang H., 2003. Remote sensing analysis of rice disease stresses for farm pest management using wide-band airborne data. International Geosciences and Remote Sensing Symposium-IV, July 21-25, 2003, Toulouse, France.

Rao, N. P. P., 1988. Remote Sensing in Plant Protection. Workshop on Agrometeorological information for planning and operation in Agriculture, Calcutta, 22-26, Aug.WMO/FAO/BCKV/IMD. pp. 129153.

Ray, R., 2001. Remote sensing uncovers insects. Available: http://macucares. com/news/print/ agnews/010402 rr htm (Retrieved 15 April 2015).

Reisig, D. and Godfrey L., 2006. Remote sensing for detection of cotton aphid- (Homoptera : Aphididae) and spider mite- (Acari : Tetranychidae) infested cotton in the San Joaquin Valley. Department of Entomology, University of California, USA.

Riley, J.R., 1989. Remote sensing in entomology. Annual Review of Entomology 34: 247-271.

Riley, J.R., Armes N.J., Reynolds, D.R. and Smith A.D., 1992. Nocturnal observations on flight behavior of Helicoverpa armigera (Lepidoptera: Noctuidae) in the post-rainy season in central India. Bulletin of Entomological Research 82: 243-256.

Rouse, J. W., Haas R. H., Schell J. A. and Deering D. W., 1973. Monitoring vegetation systems in the Great Plains with ERTS, Third ERTS Symposium, NASA SP-351 I. pp. 309-317.

Sabins, F. F., 1976. Remote Sensing- Principles and interpretation. Freeman. Available: http://www.ccrs.nrcan.gc.ca/ccrs/eduref/tutorial/indexe.html (Retrieved 15 April 2015).

Schaefer, G.W., 1976. Radar observations of insect flight. Symposium of the Royal Entomology Society, London 7: 157-197.

Shannon, C., 2000. The Geographer's Craft Project, Department of Geography, The University of Colorado at Boulder. Available: http://www.colorado. edu/geography/gcraft/notes/ remote/ remote_f. html (Retrieved 15 April 2015).

Shin, D.W., Baigorria G.A., Lim Y.K., Cocke S., LaRow T.E., O’Brien J.J. and Jones J.W., 2009. Assessing crop yield simulations with various seasonal climate data. Science and Technology Infusion Climate Bulletin. NOAA's National Weather Service. $7^{\text {th }}$ NOAA Annual Climate Prediction Application Science Workshop, Norman, OK, 24-27 October 2009.

Short, N.M., 2005. The remote sensing tutorial. NASA Godard Training Manual on the Role of Space Science and Technology for Using Remote Sensing to Monitor Earth and Distant Objects. World Spaceflight News. Available: http://fas.org:8080/irp/imint/docs/rst/ Front /tofc.html (Retrieved 15 April 2015).

Sinha, P. and Banik S., 2009. Plant disease forecasting and monitoring. An imperative in precision agriculture. Indian Farming 59 (8): 46-50.

Tempfli, K, Kerle N., Huurneman G.C. and Janssen L.L.F., 2009. Principles of Remote Sensing. ITC, Enschede, The Netherland. 
Thenkabail, P. S., 2003. Biophysical and yield information for precision farming from near-real-time and historical Landsat TM images. Int. J. Remote Sensing 24(14): 2879-2904.

Tucker, C. J., Hielkema J. U. and Roffey J., 1985. The potential of satellite remote sensing of ecological conditions of survey and forecasting Desert Locust activity. Intl. J. Remote Sensing 6 (1):127-38.

Washino, R.K. and Wood B.L., 1993. Application of Remote Sensing to Vector Arthropod surveillance and control. American Journal of Tropical Medicine and Hygiene. Available: http:// www. ciesin.org/ docs/ 001-487/ 001-487. html (Retrieved 15 April 2015).

Wood, C.R., O’Connor E. J., Hurley R. A., Reynolds D. R. and Illingworth A. J., 2008. Cloud-radar observations of insects in the UK convective boundary layer. Meteorol. Appl. 00: 1-10 (0000) DOI: 10.1002/met. Available : www.interscience.wiley.com (Retrieved 15 April 2015).

Zuly, Z., 2013. The electromagnetic spectrum. Available: www. zulyzami. Com /The + Electromagnetic+ Spectrum (Retrieved 15 April, 2015). 